\title{
Inflammatory response markers in rats undergoing abdominal surgical procedures
}

\author{
Türkay Kirdaka, Erdal Uysal' ${ }^{b}$ Efe Sezginc, Gülce Sevdar Cecen ${ }^{d}$, Sinan Cavund
}

Uludag University School of Medicine, Bursa; Gaziantep, Sanko University School of Medicine; Izmir, lzmir lnstitute of Technology, Laboratory of Nutrigenomics and Epidemiology, Turkey

\begin{abstract}
Background The aim of this study was to determine the effectiveness of cortisol, interleukin (IL)-6, C-reactive protein (CRP), and white blood cell (WBC) count as inflammatory markers to evaluate the postoperative inflammatory response associated with various abdominal surgical procedures in rats.

Methods Wistar albino rats $(\mathrm{N}=152)$ were randomly assigned to 7 groups: control, hepatectomy, splenectomy, nephrectomy, colectomy, gastrectomy, and sham. Apart from the control group, each group was then divided into 3 subgroups: 6 th, 24 th and 48 th h. Thus, a total of 19 groups were defined, each including 8 rats. At the 6 th, 24 th and 48 th $\mathrm{h}$ following the surgical procedures blood samples from each rat were collected. The plasma concentrations of IL- 6, cortisol, CRP, and WBC were measured.

Results Both the surgery category and the elapsed time after the surgery had a significant effect on IL-6 levels $(\mathrm{P}<0.0001)$. Blood CRP levels were primarily determined by the surgery category $(\mathrm{P}<0.0001)$. Neither surgery nor the elapsed time had a significant effect on the cortisol levels. The elapsed time after surgery was the major factor that influenced the differences in WBC count among the surgery groups $(\mathrm{P}<0.0001)$.

Conclusions Our results cumulatively indicate that the levels of IL-6, CRP, and cortisol and WBC count change at different time points after several abdominal surgical procedures. Cortisol level is not related to the type of surgical procedure or the elapsed time, while WBC count decreases with the elapsed time. None of the changes in the markers investigated in this study is specifically related to the category of abdominal surgical procedure.
\end{abstract}

Keywords Surgical, procedure, inflammatory, response, interleukin-6, C-reactive protein, cortisol

Ann Gastroenterol 2020; 33 (5): 1-8

\section{Introduction}

All organisms are affected by stress factors and respond to them in various ways. One stress factor is surgical trauma, which causes activation of systemic, immune and

Department of ${ }^{\mathrm{a} G e n e r a l ~ S u r g e r y, ~ U l u d a g ~ U n i v e r s i t y ~ S c h o o l ~ o f ~}$ Medicine, Bursa; 'beneral Surgery, Gaziantep, Sanko University School of Medicine; 'Food Engineering, Izmir, lzmir lnstitute of Technology, Laboratory of Nutrigenomics and Epidemiology; ${ }^{\mathrm{d}}$ Medical Pharmacology, Uludag University School of Medicine, Bursa, Turkey

Conflict of interest: None

Correspondence to: Sanko University School of Medicine, Department of General Surgery, Incilipinar Mah, Ali Fuat Cebesoy Bulv, No: 45 27090, Sehitkamil - Gaziantep, Turkey, e-mail: drerdaluysal@hotmail.com

Received 28 April 2020; accepted 9 June 2020;

published online 30 June 2020

DOI: https://doi.org/10.20524/aog.2020.0511 inflammatory responses. An acute inflammatory response can ensue following incisions associated with tissue trauma, organ manipulation, and vascular injury $[1,2]$.

At the start of a surgical procedure, the release of catecholamine, corticotrophin, growth hormone and arginine vasopressin is increased via the sympathetic nervous system as a neuroendocrine response. Following the increase in corticotrophin, secretion of cortisol in the adrenal cortex peaks after 4-6 h. The secretion of proinflammatory cytokines, such as tumor necrosis factor- $\alpha$ and interleukins (IL) 1 and 6 , is increased [3]. In clinical practice, cortisol, IL-6, C-reactive protein (CRP) and white blood cell (WBC) count are the common markers used to assess the inflammatory response [4]. Recent years have also shown that the inflammatory mediators of IL-6 and CRP can be used for early diagnosis of postoperative complications such as infection and anastomotic leakage [5-7]. However, the changes in these mediators may also be independent of any postoperative complications. In the case of uncomplicated operations, it would be valuable to know 
the magnitude of the peak response of the mediators and the time taken to reach the peak response after a surgical operation. Such information could help determine the conditions under which a change in the response of the mediators is associated with complications. Moreover, it would be useful to determine whether there are correlations among cortisol, IL-6 and WBC count for evaluating the magnitude of the inflammatory response following various abdominal surgical procedures. If such correlations exist among the mediators, an overall assessment of the correlated mediators could be a helpful strategy for postoperative evaluation.

A recent study showed that an increase in cytokine levels during the postoperative period correlates with surgical stress. The increased surgical stress is also associated with potential postoperative short- and long-term consequences [8]. Therefore, knowing the inflammatory response after various abdominal operations could help minimize surgical stress. The aim of this study was to determine the effectiveness of cortisol, IL-6, CRP and WBC count as inflammatory markers to evaluate the postoperative inflammatory response associated with various abdominal surgical procedures in rats.

\section{Materials and methods}

\section{Rat groups}

Wistar albino rats $(\mathrm{N}=152$, female, varying in weight from 260-280 g) were randomly assigned to 7 groups: control, hepatectomy, splenectomy, nephrectomy, colectomy, gastrectomy, and sham. Each group apart from the controls was then divided into 3 subgroups: $6^{\text {th }}, 24^{\text {th }}$ and $48^{\text {th }} \mathrm{h}$. Thus, a total of 19 groups were defined, each including 8 rats.

\section{Anesthesia and surgical technique}

All rats were placed in cages (4 rats per cage) with standard bedding at room temperature $\left(18-24^{\circ} \mathrm{C}\right), 12$-h light-dark cycle, and free access to standard food and water. Prior to the surgical procedure, the rats were fasted for $6 \mathrm{~h}$. For anesthesia and intraperitoneal injection, ketamine $(75 \mathrm{mg} / \mathrm{kg}$ ) (Ketalar, Pfizer, Turkey) and Xylazine (10 mg/kg) (Rompun ${ }^{\circledR}$, Bayer AG, Leverkusen, Germany) were used, respectively. For asepsis and intramuscular prophylaxis, polyvinylpyrrolidone iodine 10\% and ceftriaxone $100 \mathrm{mg} / \mathrm{kg}$ were used, respectively. Bupivacaine $0.25 \%$ was applied on incision to provide postoperative pain relief. Postoperative analgesia was performed with ketoprofen (Profenid, Sanofi Aventis, Paris, France), $3 \mathrm{mg} / \mathrm{kg}$ subcutaneously, daily. Subcutaneous infusion of $10 \mathrm{~mL} \mathrm{NaCl} 0$. 9\% was used to hydrate the rats. After the procedure, each rat was placed into its own cage and remained under observation. The rats were again given free access to food and water $5 \mathrm{~h}$ after the surgery.

A midline $5 \mathrm{~cm}$ laparotomy was performed in all rats but the controls to conduct the planned surgical procedures:
- Group 1 (control): no surgical procedure other than anesthesia.

- Group 2 (hepatectomy): using the partial hepatectomy technique described by Higgins and Anderson [9], the right medial, left medial and left lateral lobes were resected in a $70 \%$ hepatectomy.

- Group 3 (splenectomy): the splenic vein and artery were ligated using a 4/0 polyglactin suture (Vicryl, Ethicon Endo-Surgery, Cincinnati, USA) for the splenectomy [10].

- Group 4 (nephrectomy): nephrectomy was performed with the isolation of the renal hilum and ligation of the right renal artery to the ureter using a $4 / 0$ polyglactin suture (Vicryl, Ethicon Endo-Surgery, Cincinnati, USA) [11].

- Group 5 (colectomy): a $5 \mathrm{~mm}$ right colon segment $1 \mathrm{~cm}$ away from the distal part of the ileocecal valve was resected, avoiding colon bleeding. Then, a single-layer end-to-end anastomosis was applied between the proximal and distal ends using a 6/0 PDS (PDS ${ }^{\mathrm{m}}$ II [polydioxanone] Suture Ethicon, USA) atraumatic suture.

- Group 6 (gastrectomy): 70\% partial gastrectomy with standard resection of greater curvature and fundus was performed. Following the resection, gastric mucosa and serosa were closed continuously with a 6/0 PDS (PDS ${ }^{\mathrm{Tm}}$ II [polydioxanone] Suture Ethicon, USA) atraumatic suture.

- Group7 (sham): only laparotomy was performed.

Following the surgical procedures, the skin and subskin tissues of the rats were closed continuously using a 4/0 polyglactin (vicryl, polyglactin, Ethicon, USA) suture.

\section{Blood sample collection and analysis}

At the 6th, 24th and 48th $\mathrm{h}$ after the surgical procedures, the anesthetized rats were decapitated and $4 \mathrm{~mL}$ blood samples from each rat were collected immediately into tubes (BD Plymouth, UK) containing EDTA. The tubes were then centrifuged at $2000 \mathrm{rpm}$ at room temperature for $10 \mathrm{~min}$; the resulting serum was immediately frozen at $-80^{\circ} \mathrm{C}$ for later analysis. The analyses of cortisol, IL- 6 and CRP were performed in the pharmacology laboratory, and the WBC count in the biochemical laboratory. The plasma concentrations of cortisol, CRP and IL-6 were measured using an enzyme-linked immunosorbent assay (ELISA) according to the manufacturer's instructions (Cortisol: Elabscience Biotechnology Co., Ltd., Wuhan, P.R.C.; CRP: Boster Biological Technology Co., Ltd., CA; IL-6: Boster Biological Technology Co., Ltd., CA). Leukocyte count was obtained using the Cell-Dyn 3700 Hematology Analyzer (Abott, Minnesota, USA).

\section{Statistical analysis}

All statistical analyses were conducted using SAS/STAT version 9.3 (SAS Institute, Inc., Cary, North Carolina, USA). First, Kolmogorov-Smirnov and Shapiro-Wilk tests were used to assess the normal distribution assumption. 
Two-way ANOVA was used to assess the effect of surgery category and the elapsed time after surgery $\left(6^{\text {th }}, 24^{\text {th }}, 48^{\text {th }} \mathrm{h}\right)$ on IL-6, CRP and cortisol concentrations, and WBC count. Pairwise group means were compared using least-square and Tukey's studentized range $t$-tests. Uncorrected P-values are presented in the tables and figures. However, only Tukey's multiple comparison adjusted and Bonferroni multiple testing corrected P-values were considered as statistically significant $(\mathrm{P}<0.05)$.

\section{Ethics statement}

The present study was approved by the local ethics committee. The protocol was approved by the Animal Ethics Review Committee (Permit number 2015-07/04). All experiments were conducted in compliance with the relevant laws and institutional guidelines.

\section{Results}

Both the surgery category and the elapsed time after the surgery had a significant effect on IL-6 levels. In addition, a significant interaction was observed between surgery categories and the elapsed time (2-way ANOVA, $\mathrm{P}<0.0001$; Table 1). Overall, IL-6 levels were higher in the $6^{\text {th }} \mathrm{h}$ subgroup (160.33 $\mathrm{pg} / \mathrm{mL})$ than the $24^{\text {th }} \mathrm{h}$ subgroup $(138.30 \mathrm{pg} / \mathrm{mL}$; $\mathrm{P}=0.02)$ and the $48^{\text {th }} \mathrm{h}$ subgroup $(121.36 \mathrm{pg} / \mathrm{mL} ; \mathrm{P}<0.0001)$. Averaging all time subgroups, group 2 (hepatectomy) (182.35 $\mathrm{pg} / \mathrm{mL}$ ) and group 6 (gastrectomy) (182.79 pg/mL) had significantly higher IL-6 levels compared to group 1 (control) (115.89 pg/mL), group 7 (sham) $(109.91 \mathrm{pg} / \mathrm{mL})$, group 3 (splenectomy) (122.66 pg/mL), and group 5 (colectomy) $(115.84 \mathrm{pg} / \mathrm{mL})(\mathrm{P}<0.0001)$. At the $6^{\text {th }} \mathrm{h}$, the gastrectomy group had the highest IL-6 level, significantly higher than the levels in the control, sham, splenectomy and colectomy groups $(\mathrm{P}<0.0001$; Table 1$)$. At the $24^{\text {th }} \mathrm{h}$, the hepatectomy group had the highest IL-6 level, significantly higher than the levels in the control, sham, splenectomy and colectomy groups $(\mathrm{P}=0.01$; Table 1$)$. At the $48^{\text {th }} \mathrm{h}$, only the hepatectomy and gastrectomy groups were significantly higher than the sham group $(\mathrm{P}=0.01$; Table 1). A significant decrease in IL-6 levels from the $6^{\text {th }}-48^{\text {th }} \mathrm{h}$ subgroups was observed for the colectomy $(69.06 \%$; $\mathrm{P}=0.02)$ and gastrectomy (59.8\%; $\mathrm{P}=0.005)$ groups (Fig. $1 \mathrm{~A}$ ).

Blood CRP levels were primarily determined by the surgery category (2-way ANOVA $\mathrm{P}<0.0001$; Table 1): the colectomy group had significantly higher CRP levels (34.84 $\mathrm{pg} / \mathrm{mL})$ compared to the levels in the control $(14.73 \mathrm{pg} / \mathrm{mL})$, gastrectomy $(14.73 \mathrm{pg} / \mathrm{mL})$, hepatectomy $(16.29 \mathrm{pg} / \mathrm{mL})$ and nephrectomy $(17.45 \mathrm{pg} / \mathrm{mL})$ groups. The elapsed time after the surgery did not influence CRP levels significantly $(\mathrm{P}=0.6)$. However, in the colectomy group, a statistically significant 2.4fold increase in CRP levels was observed at the $48^{\text {th }} \mathrm{h}$ compared to the $6^{\text {th }} \mathrm{h}(\mathrm{P}=0.004$; Table 1, Fig. $1 \mathrm{~B})$. Neither surgery nor the elapsed time had a significant effect on cortisol levels. At the $48^{\text {th }} \mathrm{h}$, the cortisol level was slightly elevated in the gastrectomy group ( $\mathrm{P}=0.04$; Table 1, Fig. $1 \mathrm{C})$.

The elapsed time after surgery was the major factor that influenced the differences in WBC count among the surgery groups $(\mathrm{P}<0.0001 ;$ Table 1$)$. When the averages across subgroups were compared, a statistically significant decrease in leukocyte counts was observed among the groups: $6^{\text {th }} \mathrm{h}(5.75$ $\mathrm{K} / \mu \mathrm{L}), 24^{\text {th }} \mathrm{h}(4.19 \mathrm{~K} / \mu \mathrm{L}), 48^{\text {th }} \mathrm{h}(3.85 \mathrm{~K} / \mu \mathrm{L})(\mathrm{P}<0.0001) . \mathrm{A}$ greater decline in WBC count was observed between the $6^{\text {th }}$ and $24^{\text {th }} \mathrm{h}$ measurements in the colectomy and gastrectomy groups ( $\mathrm{P}=0.02$; Table 1 , Fig. $1 \mathrm{D})$.

\section{Discussion}

It is well known that metabolic, endocrine, cytokine and acute-phase responses follow trauma and surgical procedures in all organisms. The systemic inflammatory response associated with surgical procedures is crucial for catabolism, cardiovascular homeostasis and operative wound healing [12]. In this study, using rats, we investigated the effects of various abdominal surgical procedures on the systemic inflammatory response by assessing the magnitude of cortisol, IL-6 and CRP concentrations, and WBC count, at different time points, namely at the $6^{\text {th }}, 24^{\text {th }}$ and $48^{\text {th }} \mathrm{h}$ after the surgery. We specifically focused on investigating these markers because such markers are commonly used in clinical practice [4].

IL-6 is a cytokine that can be produced by many cells throughout the body, and is a useful marker to assess the systemic inflammatory response after elective operations [4]. Proinflammatory cytokines are affected by many factors. In particular, multiple factors affect IL-6. Our results showed that IL-6 levels were associated with the elapsed time after the surgery, and IL- 6 levels were higher at the $6^{\text {th }} \mathrm{h}$ than at the $24^{\text {th }}$ and $48^{\text {th }}$ $\mathrm{h}$ for all surgical groups apart from the hepatectomy group. These results are in good agreement with earlier studies [13-15]. For example, IL-6 levels were observed to increase at the $90^{\text {th }}$ and $125^{\text {th }}$ min after laparotomy [16], indicating that the inflammatory response ensues at an early stage of the operation. While the peak response of IL- 6 levels was observed between 12 and $24 \mathrm{~h}$ following the surgeries [17], this time range can be also between 2 and $48 \mathrm{~h}$ following several elective surgeries [18,19]. In our hepatectomy group, the IL- 6 level at the $24^{\text {th }} \mathrm{h}$ was higher than that at the $6^{\text {th }}$ and $48^{\text {th }} \mathrm{h}$, though the difference was not statistically significant. In fact, the IL- 6 level response was previously observed to peak at between 2 and $48 \mathrm{~h}$ after elective liver surgery [19-21]. Thus, it can be said that the peak response to liver resection was reached at a later time, considering this response peaked at the $24^{\text {th }} \mathrm{h}$ in our study.

IL-6 levels are known to decrease dramatically from the $48^{\text {th }}$ to the $72^{\text {nd }} \mathrm{h}$ after surgery, if a circulating IL-6 complication does not develop [22]. We also found that the IL-6 level at the $48^{\text {th }} \mathrm{h}$ was lower than that of the $6^{\text {th }} \mathrm{h}$. The decrease in IL-6 levels was statistically significant in the colectomy and gastrectomy groups.

Another finding of this study is that a significant association exists between the category of surgical procedure and IL-6 


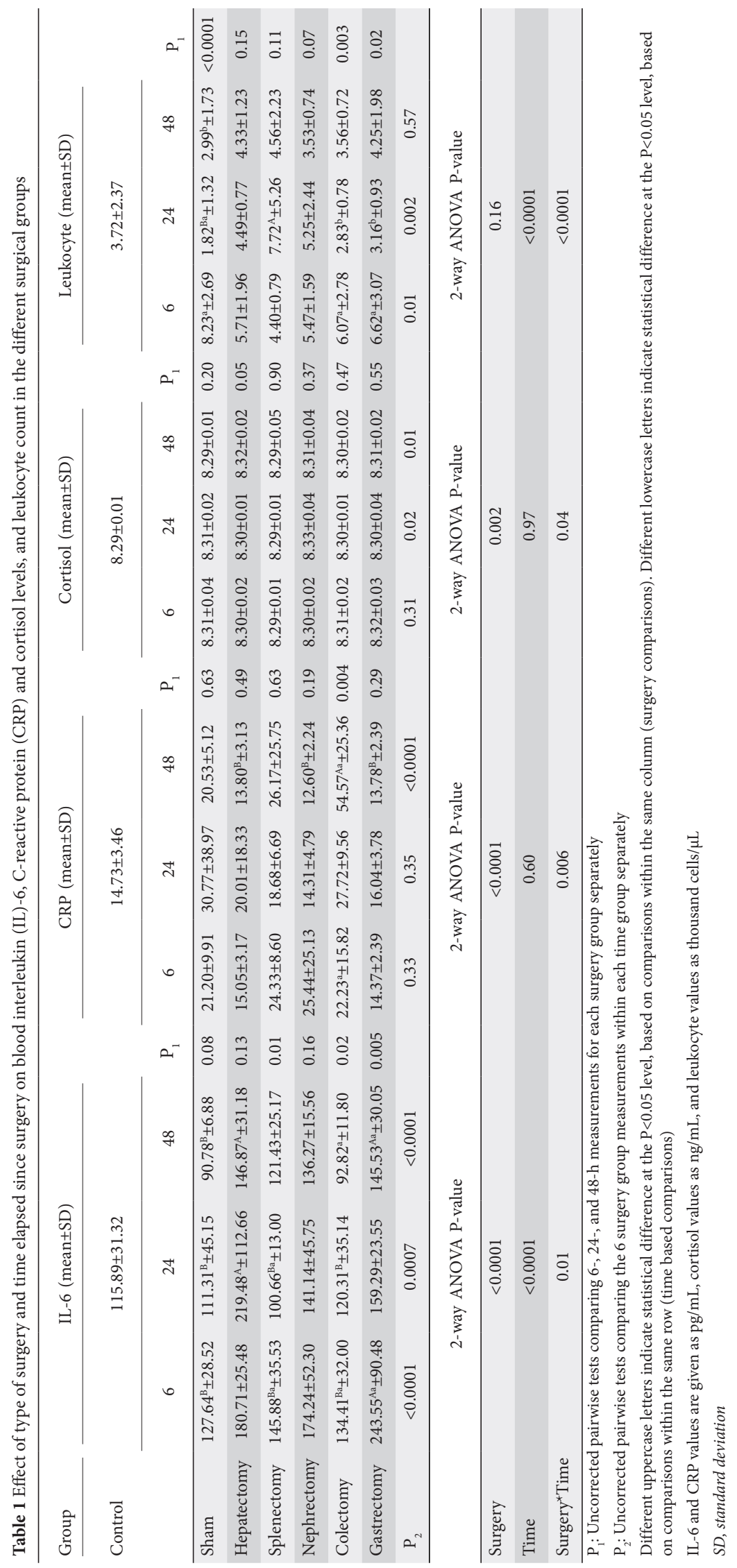




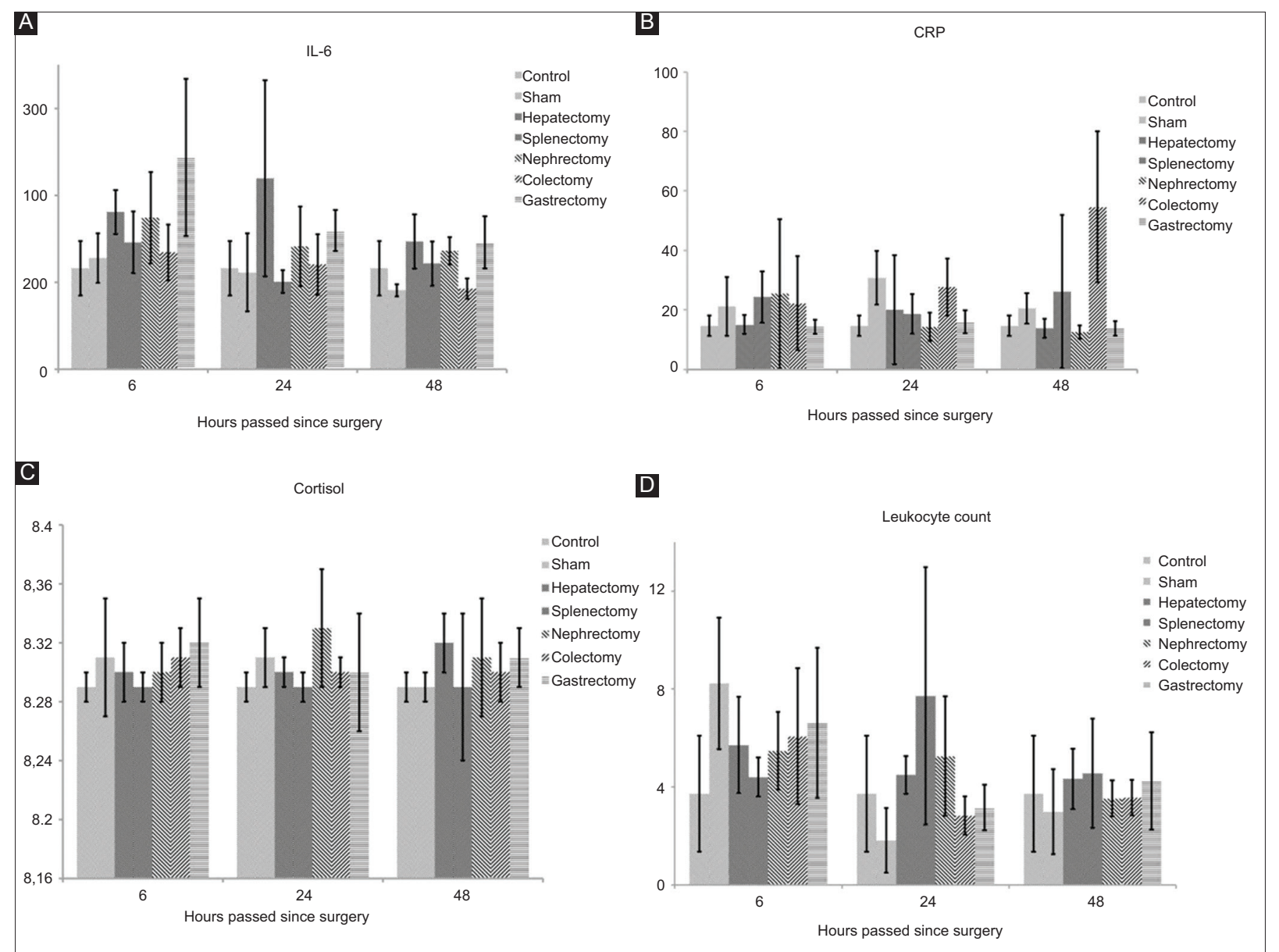

Figure 1 Comparison of (A) interleukin (IL)-6, (B) C-reactive protein (CRP), (C) cortisol, and (D) leukocyte measurements among control and surgery groups at 6,24 , and $48 \mathrm{~h}$ post-surgery. Vertical bars show standard deviations

levels. When we pooled all the data regardless of time range, the highest level of IL- 6 was found in the gastrectomy and hepatectomy groups, whereas the lowest level was found in the sham, colectomy and control groups. The differences among the groups were statistically significant $(\mathrm{P}=0.01)$. As Watt et al [4] reported in a recent systematic review, hepatectomy, colectomy, gastrectomy and nephrectomy were the surgical procedures associated with the highest IL-6 levels. When we classified the surgical procedures as minor, moderate and major operative procedures in our study, the highest levels of IL- 6 were observed in major surgical procedures. In terms of IL-6 level, the highest values in the study of Watt et al [4] were associated with hepatectomy and gastrectomy operations, comparing only those surgical procedures similar to those in our study. The IL-6 level associated with colectomy in our study was not among the top 3 highest levels, as observed in the study of Watt et al [4]. In a recent study, Glatz et al [23] investigated the local inflammatory response after colonic resection and found a statistically significantly greater IL- 6 level in the open colectomy group at the $24^{\text {th }} \mathrm{h}$ post-operation compared to that of the laparoscopic colectomy group. They indicated that the reason could be associated with the additional trauma to the abdominal wall and parietal peritoneum during a laparoscopic operation [23]. Other studies also showed that increased trauma can cause an increase in inflammatory cytokines and postoperative systemic inflammation, while intraperitoneal leakage is associated with increased levels of IL- 6 in the peritoneum $[24,25]$. Taking all into consideration, we suggest that the reason why IL-6 levels did not increase following colectomy might be because no intraabdominal infection developed and/or because there was no severe trauma or injury to the tissue and peritoneum. While IL-6 levels increase with surgical procedures, this increase is not specifically related to the category of surgical procedure.

CRP is an acute-phase protein that increases in parallel with IL-6 level, and its level generally peaks at 24-72 $\mathrm{h}$ after operative injury [4]. It is used as a marker of the systemic inflammatory response [12]. In our study, there was a statistically significant association between the category of surgical procedure and CRP level, though no significant association was found between the elapsed time after surgery and CRP level. We found that the highest CRP level was in the colectomy group, followed by the sham, splenectomy, nephrectomy and hepatectomy groups. The lowest level, on the other hand, was found in the control and the gastrectomy groups. The highest CRP level observed in the colectomy group could be due to the 
increased systemic inflammatory response associated with the translocation of colon flora, or intraabdominal infection after the resection. Based on the systematic review by Watt et al, the highest CRP level was also observed after colorectal resection, followed by gastrectomy, nephrectomy and hepatectomy [4]. Previous studies showed that CRP levels were generally lower in minor surgical procedures, such as inguinal hernia and cholecystectomy, compared to moderate surgical procedures, such as colorectal cancer resection and neurosurgical procedures [26-28]. CRP levels were also found to be lower in minimally invasive procedures, for example, laparoscopic rather than open inguinal hernia procedures [29]. Thus, as with IL-6, the magnitude of the CRP level response has been thought to be associated with the magnitude of operative injuries [4]. However, as reported in a recent systematic review [4], the peak CRP value after major liver resection, considered as a major procedure, was reported as $94 \mathrm{mg} / \mathrm{L}$, although the peak CRP value after minor liver resection, considered as a moderate procedure, was reported as $146 \mathrm{mg} / \mathrm{L}[19,20,30]$. Therefore, this finding suggests that the CRP value is not solely related to the magnitude of operative injuries. In fact, earlier studies reported that the CRP response shows patientto-patient variability [31]. In some patients, CRP may show no changes, even during inflammatory status. This condition can occur in elderly patients and liver cirrhosis [32]. Overall, we suggest that the CRP response increases with the systemic inflammatory response, but is not specific to any category of surgical procedure.

Our result also showed that the CRP level in the colectomy group increased with the elapsed time after the surgery, with the peak value being observed at the $48^{\text {th }} \mathrm{h}$. Generally, following injury, the value of CRP starts increasing at 4-6 h, and peaks at the $48^{\text {th }} \mathrm{h}$ [33], returning to its baseline value at 72$168 \mathrm{~h}$ [34]. In the splenectomy group, the CRP peak value was also observed at the $48^{\text {th }} \mathrm{h}$. However, the CRP level can reach the peak response at a different time point depending on the surgical procedure [31]. For example, the peak CRP response was observed at the $72^{\text {nd }} \mathrm{h}$ after open major liver resection, but at the $24^{\text {th }} \mathrm{h}$ after gastric bypass surgery $[30,35]$. In the study of Jiang et al, the CRP response was reported to peak at the $72^{\text {nd }} \mathrm{h}$ after laparoscopic and open splenectomy [36]. Therefore, it seems that the elapsed time to reach the peak response is associated with the category of surgical procedure.

Cortisol is a steroid hormone that increases after both minor and major surgical procedures [37,38]. Interestingly, we found that there were no significant effects of surgical procedure or elapsed time on cortisol level. One explanation for this finding is that we first collected blood samples firstly at the $6^{\text {th }} \mathrm{h}$ following the operations, whereas the cortisol level response can peak at as early as 0-4 h [4]. Furthermore, cortisol secretion is regulated by a negative feedback inhibition mechanism through adrenocorticotropic hormone; operative injury can change this feedback mechanism, leading to a constant high level of cortisol for a long time [39]. Thus, it is possible that the cortisol level in our study may have reached its peak response before the $6^{\text {th }} \mathrm{h}$ and then remained constant at a high level between the 6 and $48 \mathrm{~h}$ time points because of a disturbed feedback inhibition mechanism following operative injury. On the other hand, the cortisol levels in our study were similar among the surgical groups. In fact, cortisol peak values were previously found to be similar across a variety of surgical procedures [4]. However, the cortisol value appears slightly different when minimally invasive or laparoscopic procedures are compared with open procedures, such as the comparison between laparoscopic and open cholecystectomy, or between laparoscopic and open inguinal hernia repair [29,40]. Overall, these findings suggest that the magnitude of the cortisol level is not clearly related to the invasiveness of the elective intervention or the category of surgical procedure.

In our study, apart from the splenectomy group, we observed a statistically significant decline in total WBC count at $24 \mathrm{~h}$ compared to that at $6 \mathrm{~h}$. An increase in total WBC count followed by a decrease is observed after surgical procedures, and the increase is linked to the increased concentration of neutrophils during the first $24 \mathrm{~h}$ after surgical trauma. The neutrophils are removed from the plasma via the spleen, liver and bone marrow, resulting a decline in WBC count [41]. On the other hand, reduced concentrations of lymphocytes and polymorphonuclear leukocytes were previously reported after major surgical procedures, following an increase in WBC count in the later hours. This decrease and increase are not solely related to stress and bleeding, and tissue trauma is thought to be a major reason behind the change in WBC count [42]. In fact, Kehinde et al also reported a decline in lymphocyte counts at 2 and $24 \mathrm{~h}$, depending on surgical trauma, and Glatz et al observed a reduced number of leucocyte 3 days after colonic resection $[23,43]$. Taking all into consideration, we suggest that the decreased WBC count at the $24^{\text {th }} \mathrm{h}$ may be associated with the decrease in lymphocytes and polymorphonuclear leukocytes and/or a change in neutrophil concentration. Interestingly, we observed an increased total WBC count at the $24^{\text {th }} \mathrm{h}$ in the splenectomy group. The reason for this increase may be related to post-splenectomy leukocytosis, because it is know that post-splenectomy leukocytosis can ensue following splenectomy [44,45]. Our conclusion is therefore that the postoperative change in total WBC count is not clearly linked to the category of surgical procedure and operative trauma. Plasma cortisol concentration and the total WBC reached their peaks before the CRP: cortisol at $6 \mathrm{~h}$ and $\mathrm{WBC}$ at $12 \mathrm{~h} \mathrm{[46].}$

This study had some limitations. First, following the blood sample collection, we did not perform a secondary laparotomy to observe any intraabdominal abscess, infection and anastomotic leakage. Thus, especially in the colectomy group, the increased level of CRP at the $6^{\text {th }}, 24^{\text {th }}$ and $48^{\text {th }} \mathrm{h}$ might be associated secondarily with intraabdominal abscess and anastomotic leakage, as well as infection, because CRP can also be used a marker of intraabdominal infection after colorectal surgery [47]. Second, we only counted total WBC without differentiating the subgroups of cells. However, the change in total WBC count can be associated with the changes in neutrophils, lymphocytes and other cell types. Thus, we do not know the exact reason for the change in WBC count in this study. In fact, the assessment of postoperative changes in 
cell count subgroups is still not well established [47]. Lastly, we used different rats for each subgroup, because it was not practical to collect sufficient blood samples from each rat at multiple time points. Using an animal from which sufficient blood samples can be collected at different time points would be a more suitable way to investigate the inflammatory response of the same animal in a future study.

Our results cumulatively indicate that the levels of IL-6, CRP, and cortisol and WBC count change at different time points $\left(6^{\text {th }}, 24^{\text {th }}, 48^{\text {th }} \mathrm{h}\right)$ after several abdominal surgical procedures. Among the markers investigated, changes were observed in IL- 6 and CRP levels. While the highest value of IL- 6 was found at the $6^{\text {th }} \mathrm{h}$, there was no link between CRP level and the time elapsed after surgery. We observed the highest IL- 6 levels in the hepatectomy and gastrectomy groups, and the highest CRP levels in the colectomy and nephrectomy groups. Cortisol level was not related to the category of surgical procedure or the elapsed time, while WBC count decreased with the elapsed time. None of the changes in the markers investigated in this study was specifically related to the category of abdominal surgical procedure. In clinical practice, routine IL-6, CRP, WBC and cortisol measurement need not be performed to evaluate the postoperative inflammatory response. It may be advisable to identify specific targets for IL-6, CRP, WBC and cortisol.

\section{Summary Box}

\section{What is already known:}

- Metabolic, endocrine, cytokine and acute-phase responses follow trauma and surgical procedures in all organisms

- The highest interleukin (IL)-6 levels are observed in hepatectomy, colectomy, gastrectomy and nephrectomy; C-reactive protein (CRP) generally peaks at 24-72 $\mathrm{h}$ after operative injury; cortisol increases after both minor and major surgical procedures; total white blood cell (WBC) count may vary in the postoperative period

\section{What the new findings are:}

- The lowest IL-6 levels were found in the sham, colectomy and control groups

- CRP response increased with the systemic inflammatory response, but the increase in CRP level was not specific to the category of surgical procedure

- The surgical procedure and the elapsed time had no significant effects on cortisol level

- The postoperative change in total WBC count was not clearly linked to the category of surgical procedure or the operative trauma

\section{References}

1. Novitsky YW, Litwin DE, Callery MP. The net immunologic advantage of laparoscopic surgery. Surg Endosc 2004;18:1411-1419.

2. Buunen M, Gholghesaei M, Veldkamp R, Meijer DW, Bonjer HJ, Bouvy ND. Stress response to laparoscopic surgery: a review. Surg Endosc 2004;18:1022-1028.

3. Marik PE, Flemmer M. The immune response to surgery and trauma: implications for treatment. J Trauma Acute Care Surg 2012;73:801-808.

4. Watt DG, Horgan PG, McMillan DC. Routine clinical markers of the magnitude of the systemic inflammatory response after elective operation: a systematic review. Surgery 2015;157:362-380.

5. Cole DS, Watts A, Scott-Coombes D, Avades T. Clinical utility of peri-operative $\mathrm{C}$-reactive protein testing in general surgery. Ann $R$ Coll Surg Engl 2008;90:317-321.

6. Sammour T, Kahokehr A, Zargar-Shoshtari K, Hill AG. A prospective case-control study of the local and systemic cytokine response after laparoscopic versus open colonic surgery. J Surg Res 2012;173:278-285.

7. Yamamoto T, Umegae S, Kitagawa T, Matsumoto K. Intraperitoneal cytokine productions and their relationship to peritoneal sepsis and systemic inflammatory markers in patients with inflammatory bowel disease. Dis Colon Rectum 2005;48:1005-1015.

8. Okamura A, Takeuchi H, Matsuda S, et al. Factors affecting cytokine change after esophagectomy for esophageal cancer. Ann Surg Oncol 2015;22:3130-3135.

9. Higgins GM, Anderson RM. Experimental pathology of liver. I. Restoration of liver of the white rat following partial surgical removal. Arch Pathol 1931;12:186-202.

10. Karip B, Mestan M, Işık, et al. A solution to the negative effects of splenectomy during colorectal trauma and surgery: an experimental study on splenic autotransplantation to the groin area. BMC Surg 2015;15:129.

11. Harrison RG. The influence of unilateral nephrectomy on the production of experimental arthritis in the albino rat. $\mathrm{Br} \mathrm{Med} J$ 1951;2:1299-1304.

12. Desborough JP. The stress response to trauma and surgery. $\mathrm{Br} \mathrm{J}$ Anaesth 2000;85:109-117.

13. Greco F, Hoda MR, Mohammed N, Springer C, Fischer K, Fornara P. Laparoendoscopic single-site and conventional laparoscopic radical nephrectomy result in equivalent surgical trauma: preliminary results of a single-centre retrospective controlled study. Eur Urol 2012;61:1048-1053.

14. Servis D, Busic Z, Stipancic I, Patrlj L, Gagro A. Serum cytokine changes after gastric resection or gastrectomy for gastric cancer. Hepatogastroenterology 2008;55:1868-1872.

15. Ozawa A, Konishi F, Nagai H, Okada M, Kanazawa K. Cytokine and hormonal responses in laparoscopic-assisted colectomy and conventional open colectomy. Surg Today 2000;30:107-111.

16. Lin E, Calvano SE, Lowry SF. Inflammatory cytokines and cell response in surgery. Surgery 2000;127:117-126.

17. Cruickshank AM, Fraser WD, Burns HJ, Van Damme J, Shenkin A. Response of serum interleukin-6 in patients undergoing elective surgery of varying severity. Clin Sci (Lond) 1990;79:161-165.

18. Hadimioglu N, Ulugol H, Akbas H, Coskunfirat N, Ertug Z, Dinckan A. Combination of epidural anesthesia and general anesthesia attenuates stress response to renal transplantation surgery. Transplant Proc 2012;44:2949-2954.

19. Jansen MC, van Wanrooy S, van Hillegersberg R, et al. Assessment of systemic inflammatory response (SIR) in patients undergoing radiofrequency ablation or partial liver resection for liver tumors. Eur J Surg Oncol 2008;34:662-667.

20. Lan AK, Luk HN, Goto S, et al. Stress response to hepatectomy in patients with a healthy or a diseased liver. World J Surg 2003;27:761-764. 
21. Strey CW, Marquez-Pinilla RM, Markiewski MM, et al. Early postoperative measurement of cytokine plasma levels combined with pre-operative bilirubin levels identify high-risk patients after liver resection. Int J Mol Med 2011;27:447-454.

22. Baigrie RJ, Lamont PM, Kwiatkowski D, Dallman MJ, Morris PJ. Systemic cytokine response after major surgery. $\mathrm{Br} J$ Surg 1992;79:757-760.

23. Glatz T, Lederer AK, Kulemann B, et al. The degree of local inflammatory response after colonic resection depends on the surgical approach: an observational study in 61 patients. BMC Surg 2015; 15:108

24. Schietroma M, Carlei F, Mownah A, et al. Changes in the blood coagulation, fibrinolysis, and cytokine profile during laparoscopic and open cholecystectomy. Surg Endosc 2004;18:1090-1096.

25. Fouda E, El Nakeeb A, Magdy A, Hammad EA, Othman G, Farid M. Early detection of anastomotic leakage after elective low anterior resection. J Gastrointest Surg 2011;15:137-144.

26. Uzunköy A, Coskun A, Akinci OF, Kocyigit A. Systemic stress responses after laparoscopic or open hernia repair. Eur J Surg 2000;166:467-471.

27. McMahon AJ, O’Dwyer PJ, Cruikshank AM, et al. Comparison of metabolic responses to laparoscopic and minilaparotomy cholecystectomy. Br J Surg 1993;80:1255-1258.

28. Delgado S, Lacy AM, Filella X, et al. Acute phase response in laparoscopic and open colectomy in colon cancer: randomized study. Dis Colon Rectum 2001;44:638-646.

29. Akhtar K, Kamalky-asl ID, Lamb WR, et al. Metabolic and inflammatory responses after laparoscopic and open inguinal hernia repair. Ann R Coll Surg Engl 1998;80:125-130.

30. Rahman SH, Evans J, Toogood GJ, Lodge PA, Prasad KR. Prognostic utility of postoperative C-reactive protein for posthepatectomy liver failure. Arch Surg 2008;143:247-253.

31. Santonocito C, De Loecker I, Donadello K, et al. C-reactive protein kinetics after major surgery. Anesth Analg 2014;119:624-629.

32. Pieri G, Agarwal B, Burroughs AK. C-reactive protein and bacterial infection in cirrhosis. Ann Gastroenterol 2014;27:113-120.

33. White J, Kelly M, Dunsmuir R. C-reactive protein level after total hip and total knee replacement. J Bone Joint Surg Br 1998;80:909-911.

34. Gabay C, Kushner I. Acute-phase proteins and other systemic responses to inflammation. $N$ Engl J Med 1999;340:448-454.
35. Csendes A, Burgos AM, Roizblatt D, Garay C, Bezama P. Inflammatory response measured by body temperature, $\mathrm{C}$-reactive protein and white blood cell count 1,3 , and 5 days after laparotomic or laparoscopic gastric bypass surgery. Obes Surg 2009;19:890-893.

36. Jiang GQ, Chen P, Qian JJ, et al. Perioperative advantages of modified laparoscopic vs open splenectomy and azygoportal disconnection. World J Gastroenterol 2014;20:9146-9153.

37. Smeets HJ, Kievit J, Dulfer FT, van Kleef JW. Endocrine-metabolic response to abdominal aortic surgery: a randomized trial of general anesthesia versus general plus epidural anesthesia. World J Surg 1993;17:601-606.

38. Nguyen NT, Goldman CD, Ho HS, Gosselin RC, Singh A, Wolfe BM. Systemic stress response after laparoscopic and open gastric bypass. J Am Coll Surg 2002;194:557-566.

39. Weissman C. The metabolic response to stress: an overview and update. Anesthesiology 1990;73:308-327.

40. Joris J, Cigarini I, Legrand M, et al. Metabolic and respiratory changes after cholecystectomy performed via laparotomy or laparoscopy. Br J Anaesth 1992;69:341-345.

41. Kolaczkowska E, Kubes P. Neutrophil recruitment and function in health and inflammation. Nat Rev Immunol 2013;13:159-175.

42. Kirov SM, Shepherd JJ, Donald KD. Intraoperative and postoperative changes in peripheral white blood cell counts: the contribution of stress. Aust N Z J Surg 1979;49:738-742.

43. Kehinde MO, Akinyanju OO. The pattern of leucocyte response to surgical trauma in the African Negro. Clin Lab Haematol 1988;10:285-293.

44. Juneja S, Januszewicz E, Wolf M, Cooper I. Post-splenectomy lymphocytosis. Clin Lab Haematol 1995;17:335-337.

45. Djaldetti M, Bergman M, Salman H, Cohen AM, Fibach E, Bessler H. On the mechanism of post-splenectomy leukocytosis in mice. Eur J Clin Invest 2003;33:811-817.

46. Colley CM, Fleck A, Goode AW, Muller BR, Myers MA. Early time course of the acute phase protein response in man. J Clin Pathol 1983;36:203-207.

47. Domínguez-Comesaña E, Estevez-Fernández SM, López-Gómez V, Ballinas-Miranda J, Domínguez-Fernández R. Procalcitonin and C-reactive protein as early markers of postoperative intraabdominal infection in patients operated on colorectal cancer. Int J Colorectal Dis 2017;32:1771-1774. 